DOI: 10.4274/tod.07769

\title{
Osteoporozda Yaşam Kalitesi: Bir Kontrollü Çalışma
}

\author{
Quality of Life in Osteoporosis: A Controlled Study
}

Halim Yılmaz, Gülten Erkin, Halime Almula Demir Polat*, Sami Küçükşen**, Ali Sallı**, Hatice Uğurlu**

Konya Eğitim ve Araştırma Hastanesi, Fiziksel Tıp ve Rehabilitasyon Kliniği, Konya, Türkiye

*Afyonkarahisar Devlet Hastanesi, Fiziksel Tıp ve Rehabilitasyon Kliniği, Afyon, Türkiye

**Necmettin Erbakan Universitesi Meram Tıp Fakültesi, Fiziksel Tıp ve Rehabilitasyon Kliniği, Konya, Türkiye

\section{Ozzet}

Amaç: Bu çalışmada vertebral veya non-vertebral kırığı olmayan postmenopozal osteoporozlu (PMO), osteopenik ve normal kemik mineral yoğunluğuna (KMY) sahip kadınların yaşam kalitesini değerlendirmek ve yaşam kalitesi üzerine etkili faktörleri belirlemek amaçlandı.

Gereç ve Yöntemler: Kırığı olmayan PMO'lu 266 kadın, 310 osteopenik kadın ve 255 normal KMY'li kadın çalışmaya alındı. KMY ölçümü, dual enerji X-ray absorbsiyometri (DXA) ile lomber vertebra (L1-4) ve femur boyundan yapıldı. Yaşam kalitesi Avrupa Osteoporoz Kurumu Yaşam Kalitesi Anketi (QUALEFFO) kullanılarak değerlendirildi. Grupların QUALEFFO total skorları ve alt grup skorları karşılaştırıldı. Korelasyon analizi ile PMO'lu kadınlarda yaşam kalitesi ile ilişkili faktörler belirlendi. Yaşam kalitesi ile en yüksek korelasyona sahip değişkenler lineer regresyon modeline alındı. Bulgular: Kırığı olmayan PMO'lu kadınlarda QUALEFFO total skor ve alt grup skorları osteopenik ve normal KMY'e sahip gruba göre anlamlı derecede yüksekti. PMO'lu kadınlarda QUALEFFO total skoru ile yaş, vücut kitle indeksi (VKi), doğum sayısı ve menapoz süresi arasında pozitif korelasyon, eğitim düzeyi, gelir düzeyi, femur boyun KMY skorları arasında negatif korelasyon tespit edildi. Lineer regresyon analizi sonucunda, yaşam kalitesinin en önemli belirleyicileri olarak VKi, femur boyun KMY, doğum sayısı ve menapoz süresi tespit edildi.

Sonuç: Bu çalışmanın sonuçları kırığı olmayan PMO'lu kadınların yaşam kalitelerinin osteopenik ve normal KMY'ye sahip kadınlara göre belirgin derecede bozulduğunu ve yaşam kalitesinin birçok faktörden etkilendiğini göstermektedir. (Türk Osteoporoz Dergisi 2012;18: 47-52)

Anahtar kelimeler: Postmenopozal osteoporoz, yaşam kalitesi, QUALEFFO, kemik mineral yoğunluğu.

\section{Summary}

Aim: To evaluate quality of life in women without vertebral and nonvertebral fractures, with postmenopausal osteoporosis (PMO), osteopenic and normal bone mineral density (BMD), and to determine effective factors on quality of life.

Materials and Methods: Without fractures, 266 women with PMO, 310 with osteopenia and 255 with normal women BMD were enrolled in the study. BMD measurement was performed on lumbar vertebra (L1-L4) and femur neck via dual energy X-ray absorbtiometry (DXA). Quality of life was assessed with Quality of Life Questionnaire of the European Foundation for Osteoporosis (QUALEFFO). QUALEFFO total scores and subscales were compared in all groups. Factors about quality of life in women with PMO were defined with correlation analysis. Variations of the highest correlation and quality of life were included into linear regression model.

Results: In non-fractured women with PMO, QUALEFFO total scores and subscales were higher than those with osteopenia and normal BMD. In women with PMO, a positive correlation was found between QUALEFFO total scores, and age, Body Mass index (BMI), parity and duration of menopause, and a negative correlation between QUALEFFO total scores, and level of education, economical status and femur neck BMD scores. In linear regression analysis, among significant factors of quality of life were BMI, femur neck BMD, parity and duration of menopause.

Conclusion: Our results indicate that quality of life in non-fractured women with PMO is disordered higher than those with osteopenia and normal BMD, and quality of life are affected by numerous factors. (Turkish Journal of Osteoporosis 2012;18: 47-52)

Key words: Postmenopausal osteoporosis, quality of life, QUALEFFO, bone mineral density

Yazışma Adresi/Address for Correspondence: Dr. Halim Yılmaz, Konya Eğitim ve Araștırma Hastanesi Fiziksel Tıp ve Rehabilitasyon Kliniği, Konya, Türkiye Tel.: +90 3323236709 GSM: +90 5058544614 E-mail: drhalimyilmaz@hotmail.com Geliș Tarihi/Received: 13.08.2012 Kabul Tarihi/Accepted: 27.08 .2012 Turkish Journal of Osteoporosis, published by Galenos Publishing. / Türk Osteoporoz Dergisi, Galenos Yayınevi tarafindan basılmıştır. 


\section{Giriş}

Yaşam kalitesi; kişinin yaşadığı kültür ve değer sistemleri çerçevesinde, amaçları, beklentileri, standartları ve ilgileri ile ilişkili olarak yaşamdaki pozisyonunu algılaması şeklinde tanımlanır. Sağlıkla ilişkili yaşam kalitesi ise; fiziksel, sosyal ve emosyonel iyilik halini içeren yaşam kalitesinin bir alt bileşenidir $(1,2)$. Osteoporoz, düşük kemik kütlesi ve kemik mikromimarisindeki bozulmayla karakterize, kemiğin frajilitesinde artışa yol açan metabolik bir kemik hastalığıdır $(3,4)$. Başta postmenopozal kadınlar olmak üzere ileri yaştaki birçok kişiyi etkilemektedir. Osteoporoz, ağrı, sırt kas gücünde azalma, esneklik kaybı, şekil bozuklukları, duygu durumundaki değişiklikler, vertebral veya non-vertebral kırığa neden olarak hastaların yaşam kalitesini olumsuz etkileyebilmektedir $(2,5,6,7)$. Osteoporozun yaşam kalitesine etkisi son yıllarda ilgi çekmeye başlamış ve yaşam kalitesi klinik çalışmalarda sık olarak değerlendirilmeye başlanmıştır. Daha önce yürütülen çalışmaların çoğu osteoporoza bağlı vertebral ve nonvertebral kırıkların yaşam kalitesi üzerindeki etkilerini incelemiştir $(8,9,10,11,12)$. Ancak kırığı olmayan $\mathrm{PMO}^{\prime} l u$ kadınlarda yaşam kalitesi ve yaşam kalitesi üzerine etkili faktörleri inceleyen çalışma sayısı kısıtlıdır. Biz bu çalışmada, kırığı olmayan PMO'lu kadınlarda osteoporoza özgü yaşam kalitesi ölçeği olan QUALEFFO kullanarak yaşam kalitesi ve yaşam kalitesi üzerine etkili faktörleri araştırmayı amaçladık.

\section{Gereç ve Yöntem}

Çalışmamıza Temmuz 2010-Temmuz 2012 tarihleri arasında Konya Eğitim ve Araştırma Hastanesi Fizik Tedavi ve Rehabilitasyon Polikliniğine başvuran hastalardan, 40 yaş ve üzeri, Dünya Sağlık Örgütü (DSÖ) kriterlerine göre PMO tanısı alan, vertebral veya non-vertebral kırığı olmayan 266 kadın, osteopeni tanısı alan 310 ve normal KMY'li 255 kadın dahil edildi. Çalışmanın yapılabilmesi için Selçuk Üniversitesi Meram Tıp Fakültesinden Lokal Etik Kurul izni alındı. Çalışmaya katılmayı kabul eden hastalar bilgilendirildi ve imzalı onam formları alındı. Değerlendirme formu ile katılımcıların sosyodemografik ve klinik özellikleri belirlendi. Hastaların vücut ağırıkları ve boyları ölçülerek VKi'leri hesaplandı.

Kullanılan anket formundaki istenen basit soruları anlayabilen ve cevaplayabilenler çalışmaya dahil edildi. Iletişim kurmayı engelleyecek mental, işitsel ve görsel problemi olanlar, yardımcı cihaz kullananlar, ciddi sistemik hastalığı, yaşam kalitesi üzerinde belirgin etki gösterebilecek bir romatolojik, ortopedik ve nörolojik problemi, osteoporoz dışında metabolik kemik hastalığı, bel ağrısına yol açabilecek hastalığı, malignite, renal yetmezlik, kronik respiratuvar hastalığı, kardiyovasküler hastalığı, diabetes mellitus, majör psikiatrik hastalığı, osteomalazi, hiperparatiroidi, sekonder osteoporoza yol açacak bir kronik hastalığı veya ilaç kullanımı, 40 yaşından önce menopoz öyküsü, cerrahi menopoz öyküsü olanlar, son iki yılda kalsiyum ve D vitamini dışında kemik metabolizmasını etkileyebilecek ilaç kullananlar, düzenli fiziksel egzersiz yapanlar, alkol ve sigara kullanım öyküsü, T4-L5 arasındaki herhangi bir vertebrada kırık tespit edilenler (14), ya da vertebra dışında osteoporoza bağlı kırık tespit edilenler ve kırık öyküsü olanlar çalışmaya alınmadı.
Katılımcıların KMY ölçümleri, DXA ile ön-arka projeksiyonda, lumbar vertebradan (L1-4 vertebra) ve femur boyundan ölçüldü. KMY değerleri gr/cm2 olarak ve pik genç erişkin kemik yoğunluk değerine göre belirlenen T skorları ile değerlendirildi. DSÖ tanımlanmasına göre aynı cins erişkinlerin ortalamasına göre $T$ skoru -1 standart deviasyona (SD) kadar olan KMY 'normal', T skoru aynı cins erişkinlerin ortalamasına göre -1 ve -2,5 SD arasında olan KMY değerleri 'osteopeni', T skoru aynı cins erişkinlerin ortalamasına göre $-2,5$ SD'un altında olan KMY değerleri 'osteoporoz' olarak değerlendirildi (4).

Katılımcıların dorsolomber lateral radyografileri çekildi. Vertebral deformite ve fraktür varlığı, standardize torasik ve lomber omurga grafileri üzerinde Genant Metodu kullanılarak değerlendirildi Genant metoduna göre morfometri Torakal-4-Lomber-5'den yapıldı (13).

Katılımcıların yaşam kaliteleri Türkçe geçerlilik ve güvenirliliği de gösterilmiş olan QUALEFFO ölçeği ile değerlendirildi (14). QUALEFFO hastalık spesifik değerlendirme ölçeklerinden biridir. Bu anket ağrı, fiziksel fonksiyon, sosyal fonksiyon, genel sağlık değerlendirmesi ve mental fonksiyon olmak üzere 5 alt gruptan oluşmaktadır ve toplam 41 soru içermektedir. QUALEFFO total ve alt ölçekler bazında 0-100 arası skorlanmakta olup, yüksek skor düşük yaşam kalitesini göstermektedir (14).

Rutin laboratuvar testlerinin yanısıra, serumda Parathormon (PTH), kalsiyum, fosfor, alkalen fosfataz (ALP) ölçümleri yapıldı. Sekonder osteoporozu dışlamak için gereği durumunda ilave tetkikler yapıldı.

\section{İstatistiksel Analiz}

İstatistiksel değerlendirmeler için SPSS 20 paket programı kullanıldı. Tanımlayıcı istatistik sonuçları ort \pm Ss olarak verildi. Grupların öğrenim, çalışma ve medeni durumları çapraz tablolar kullanılarak değerlendirildi. Gruplar arasında bu sıklıklar bakımından fark bulunup bulunmadığı Ki-Kare ya da Fisher testleri ile belirlendi. Osteoporoz, osteopeni ve normal KMY'li grupların sosyodemografik ve klinik özelliklerinin karşılaştırılmasında ANOVA testi uygulandı. Gruplar arasında QUALEFFO total skoru ve alt grup skorları bakımından fark bulunup bulunmadığının değerlendirilmesinde BMI, menopoz süresi, eğitim durumu ve yaş covariate alınarak ANCOVA testi yapıldı. Post hoc analiz olarak Bonferroni testi yapıldı. Bağımsız değişkenler ile QUALEFFO total skoru ve alt grup skorları arasındaki korelasyonların hesaplanması için Spearman rho korelasyon analizi kullanıldı. Çalışmamızın ana temasını oluşturan PMO'lu kadınlarda yaşam kalitesini belirleyen parametrelerin etki derecelerinin ortaya çıkarılması için, yaşam kalitesi ile en yüksek korelasyona sahip değişkenler lineer regresyon modeline alındı. İstatistiksel anlamlılık düzeyi $p<0.05$ ve güven aralığı \%95 (\%95 Cl) olarak belirlendi. Korelasyon katsayılarında 0-0,25 arası korelasyon yok, 0,25-0.50 zayıf-orta korelasyon, 0,50-0,75 iyi korelasyon, 0,75-1,00 arası ise çok iyi korelasyon olarak değerlendirildi.

\section{Bulgular}

Grupların sosyodemografik ve klinik özellikleri Tablo 1'de, QUALEFFO total skorları, alt grup skor ortalamaları Tablo 2'de verilmiştir. Osteoporotik grubun QUALEFFO total skoru, QUALEFFO tüm alt grup ortalama skorları (ağrı, fiziksel fonksiyon, sosyal etkinlikler, genel sağlık değerlendirmesi, zihinsel fonksiyon) hem 
osteopenik hem de normal KMY'li gruba göre önemli derecede yüksekti $(p<0,001)$. Osteopenik grup ile normal $K M Y^{\prime} l i$ grup QUALEFFO total skoru ve tüm alt grup ortalama skorları arasında istatistiksel olarak anlamlı fark yoktu $(p>0,05)$. PMO'lu grubun demografik ve klinik verileri ile yaşam kalitesi skorları arasında yapılan korelasyon analizinde, yaş, VKi, doğum sayısı ve menopoz süresi ile QUALEFFO total skoru arasında istatistiksel olarak anlamlı pozitif yönde korelasyon saptandı. (sırasıyla r: 0. 0,332 $p<0,001, r: 0,172$ p:0,007, r: 0,300 p<0,001, r:0,357 p<0,001). PMO'lu grupta eğitim düzeyi, aylık gelir düzeyi ve femur boyun KMY değerleri ile QUALEFFO total skoru arasında istatistiksel olarak anlamlı negatif yönde korelasyon saptandı. (sırasıyla $r:-0,200$ p:0,001, r:-185 p:0,004, r:-272 p<0,001). Osteopeni ve normal KMY'li kadınlarda da VKi ile QUALEFFO total skoru arasında istatistiksel olarak anlamlı pozitif yönde korelasyon saptandı (sırasıyla r:-0,197, p:0,001, r:-0,202, p:0.001). PMO'lu grupta L1-4 KMY değeri ile QUALEFFO total ve alt grup skorları arasında istatistiksel olarak anlamlı korelasyon saptanmadı (r:082, $p>0,05)$. PMO'lu grupta femur boyun KMY ile QUALEFFO alt gruplarından sadece fiziksel fonksiyon skoru arasında istatistiksel olarak anlamlı negatif yönde korelasyon saptandı. (r:-0.282 $\mathrm{p}<0,001$ ) (Tablo 3).

PMO'lu kadınlarda yaşam kalitesi ile aralarında en yüksek korelasyon tespit edilen parametreler, lineer regresyon modeline alındığında yaşam kalitesinin en önemli belirleyicileri olarak VKi, femur boyun KMY, doğum sayısı ve menopoz süresi tespit edildi (sırasıyla $\beta: 5,973 p<0.001, \beta$ : $-3,897 p<0.001, \beta$ : 3,745, $p<0,001$, $\beta:$ 2,859 p:0.004) (Tablo 4)

\section{Tartışma}

Tüm dünyada önemli bir sağlık sorunu olan osteoporoz, hastaların iyilik hali ve yaşam kalitesini olumsuz etkileyebilen kronik bir hastalıktır. Bu nedenle, osteoporotik hastalarda yaşam kalitesi düzeyinin değerlendirilmesinin ve yaşam kalitesi üzerinde belirleyici olan faktörlerin ortaya çıkarılmasının önemi giderek

Tablo 1. Katılımcların demografik ve klinik verileri

\begin{tabular}{|c|c|c|c|c|c|}
\hline & $\begin{array}{c}\text { Normal KMY } \\
(n: 255)\end{array}$ & $\begin{array}{l}\text { Osteopeni grubu } \\
(n: 310)\end{array}$ & $\begin{array}{l}\text { Osteoporoz grubu } \\
(n: 266)\end{array}$ & $\mathbf{F}$ & $p$ \\
\hline Yaş(yıl) & $55,2 \pm 7,6 b, c$ & $60,6 \pm 8,6 a, c$ & $63,6 \pm 8,5^{a, b}$ & 69,997 & $<0,001$ \\
\hline $\operatorname{VKi}\left(\mathrm{kg} / \mathrm{m}^{2}\right)$ & $30,6 \pm 4,9$ & $29,7 \pm 5,3$ & $27,2 \pm 5,1 a, b$ & 30,540 & $<0,001$ \\
\hline Aylık geliri (TL) & $808,3 \pm 369,3 c$ & $739,9 \pm 358,4$ & $686,4 \pm 368,2^{a}$ & 6,927 & 0,001 \\
\hline Illk gebelik yaşı (yıl) & $20,0 \pm 3,0 c$ & $19,9 \pm 3,3 c$ & $19,7 \pm 3,7 a, b$ & 0,558 & 0,572 \\
\hline Doğum sayısı & $3,9 \pm 1,9 c$ & $4,1 \pm 2,2^{c}$ & $4,9 \pm 2,5 a, b$ & 15,829 & $<0,001$ \\
\hline Menarj yaşı (yıl) & $13,9 \pm 1,7 c$ & $14,4 \pm 5,8 c$ & $14,8 \pm 6,4 a, b$ & 5,394 & 0,005 \\
\hline Laktasyon süresi (ay) & $51,1 \pm 33,6 c$ & $57,0 \pm 38,3 c$ & $70,9 \pm 40,4 a, b$ & 18,492 & $<0,001$ \\
\hline Menepoz yaşı (yıl) & $47,6 \pm 4,2 c$ & $47,1 \pm 4,2^{c}$ & $46,3 \pm 4,2 a, b$ & 6,974 & 0,001 \\
\hline Menepoz süresi (yıl) & $7,8 \pm 7,8^{b, c}$ & $13,6 \pm 8,8 a, c$ & $17,4 \pm 9,3 a, b$ & 79,466 & $<0,001$ \\
\hline Medeni durumu & & & & $\chi^{2}$ & $p$ \\
\hline Evli & $247(\% 96,9)$ & $298(\% 96,1)$ & $221(\% 83,1)$ & 41,756 & $<0,001$ \\
\hline Bekar & $1(\% 0,4)$ & $2(\% 0,6)$ & $8(\% 3)$ & & \\
\hline Boşanmış-Dul & $7(\% 2,7)$ & $10(\% 3,2)$ & $37(\% 13,9)$ & & \\
\hline Çalışma Durumu & & & & 2,133 & 0,344 \\
\hline Çalışıyor & $0(\% 0)$ & $0(\% 0)$ & $0(\% 0)$ & & \\
\hline Çalışmıyor & $251(\% 94,4)$ & $299(\% 96,5)$ & $240(\% 94,1)$ & & \\
\hline Emekli & $15(\% 15,6)$ & $11(\% 3,5)$ & $15(\% 5,9)$ & & \\
\hline Öğrenim Durumu & & & & 32,795 & $<0,001$ \\
\hline Okur-yazar değil & $103(\% 38,7)$ & $81(\% 26,1)$ & $47(\% 18,4)$ & & \\
\hline illköğrenim (8 yıl) & $155(\% 58,3)$ & $219(\% 70,6)$ & $189(\% 74,2)$ & & \\
\hline Lise (11 yıl) & $4(\% 1,5)$ & $3(\% 1)$ & $7(\% 2,7)$ & & \\
\hline Yüksek öğrenim (12 yıl ve üzeri) & $4(\% 1,5)$ & $7(\% 2,3)$ & $12(\% 4,7)$ & & \\
\hline \multicolumn{6}{|l|}{$\begin{array}{l}\text { a Normal KMY'e sahip gruba göre } p<0,05 \\
\text { b Osteopenik gruba göre } p<0,05 \\
\text { c Osteoporotik gruba göre } p<0,05 \\
\text { VKi: Vücut Kitle indeksi }\end{array}$} \\
\hline
\end{tabular}


Tablo 2. Katılımcların KMY ve QUALEFFO ölçeği alt grup skorlarının karșılaștırılması

\begin{tabular}{|c|c|c|c|c|c|}
\hline & $\begin{array}{c}\text { Normal KMY'li } \\
\text { grup }(n=255)\end{array}$ & $\begin{array}{l}\text { Osteopeni grup } \\
\quad(n=310)\end{array}$ & $\begin{array}{l}\text { Osteoporoz grup } \\
(n=266)\end{array}$ & $\mathbf{F}$ & $\mathbf{P}$ \\
\hline \multicolumn{6}{|l|}{ KMY T-skor(ort \pm SD) } \\
\hline L1-4 KMY & $1,16 \pm 0,11 b, c$ & $0,99 \pm 0,11 a, c$ & $0,81 \pm 0,82^{a, b}$ & 792,611 & $<0,001$ \\
\hline L1-4 T-skoru & $0,18 \pm 0,89 b, c$ & $-1,3 \pm 0,84 a, c$ & $-2,82 \pm 0,65^{a, b}$ & 891,826 & $<0,001$ \\
\hline Femur boyun KMY & $0,97 \pm 0,10 b, c$ & $0,82 \pm 0,10 \mathrm{a}, \mathrm{c}$ & $0,73 \pm 0,12^{a, b}$ & 313,082 & $<0,001$ \\
\hline Femur boyun T- skoru & $0,15 \pm 0,81 b, c$ & $-1,13 \pm 0,74 a, c$ & $-1,86 \pm 1,01 a, b$ & 357,473 & $<0,001$ \\
\hline \multicolumn{6}{|l|}{ QUALEFFO } \\
\hline Ağrı & $47,67 \pm 28.51 c$ & $52,15 \pm 26,51 c$ & $59,56 \pm 24,07 a, b$ & 14,628 & $<0,001$ \\
\hline Fiziksel fonksiyon & $37,17 \pm 17,83 c$ & $40,05 \pm 18,88^{c}$ & $46,05 \pm 20,48 \mathrm{a}, \mathrm{b}$ & 16,073 & $<0,001$ \\
\hline Sosyal fonksiyon & $49,26 \pm 20,09 c$ & $52,31 \pm 20,20 c$ & $59,94 \pm 19,40^{a, b}$ & 21,449 & $<0,001$ \\
\hline Genel sağlık algılanması & $62,26 \pm 19,90 c$ & $61,95 \pm 21,85 c$ & $68,29 \pm 20,65 a, b$ & 8,387 & $<0,001$ \\
\hline Mental fonksiyon & $39,71 \pm 11,06 c$ & $41,37 \pm 9,49 c$ & $44,03 \pm 7,86 a, b$ & 13,768 & $<0,001$ \\
\hline QUALEFFO- Total & $42,43 \pm 12,84 c$ & $45,10 \pm 13,88 c$ & $50,69 \pm 13,34 a, b$ & 24,593 & $<0,001$ \\
\hline $\begin{array}{l}\text { a Normal KMY'e sahip gruba gö } \\
\text { b Osteopenik gruba göre } p<0,05 \\
\text { ' Osteoporotik gruba göre } p<0,0 \\
\text { KMY: Kemik mineral yoğunluğu } \\
\text { QUALEFFO: Avrupa Osteoporoz }\end{array}$ & Anketi & & & & \\
\hline
\end{tabular}

Tablo 3. PMO'lu kadınlarda yașam kalitesi ile demografik ve klinik veriler arasındaki ilișki

\begin{tabular}{|l|c|c|}
\hline \multirow{2}{*}{} & \multicolumn{2}{|c|}{ QUALEFFO Total } \\
\cline { 2 - 3 } & $\mathbf{r}$ & $\mathbf{p}$ \\
\hline Yaş & 0,332 & $\mathrm{P}<0,001$ \\
\hline VKi & 0,185 & 0,004 \\
\hline Eğitim düzeyi & $-0,200$ & 0,001 \\
\hline Aylık gelir miktarı & $-0,168$ & $\mathrm{P}<0,001$ \\
\hline Menopoz yaşı & $-0,73$ & 0,249 \\
\hline Menopoz süresi & 0,357 & $\mathrm{P}<0,001$ \\
\hline L1-4 KMY & 0,83 & 0,194 \\
\hline Femur boyun KMY & $-0,272$ & $\mathrm{P}<0,001$ \\
\hline Doğum sayısı & 0,300 & $\mathrm{P}<0,001$ \\
\hline $\begin{array}{l}\text { Çalışma durumu } \\
\text { VKi: Vücut Kitle indeksi KMY: Kemik mineral yoğunluğu } \\
\text { QUALEFFO: Avrupa Osteoporoz Kurumu Yaşam Kalitesi }\end{array}$ & 0,536 \\
\hline Questionnaire of the European Foundation for Osteoporosis) & \\
\hline
\end{tabular}

artmaktadır (15). Ayrıca osteoporozlu hastalarda yaşam kalitesinin değerlendirilmesi klinik olarak tedavi stratejilerini belirleme ve tedavi etkinliğini değerlendirmede önemli bir yer tutmaktadır. Sağlıkla ilişkili yaşam kalitesi genel veya hastalığa özgü olan ölçüm metodları kullanılarak değerlendirilebilir. Genel ölçümler hastalık durumlarında yaşam kalitesini değerlendirmek için kullanılabilmektedir. Fakat hastalığa özgü testlerin genel testlere göre ilgili hastalık için geçerlilikleri daha fazladır. Biz kırı̆̆ı
Tablo 4. PMO'lu kadınlarda yașam kalitesi üzerinde en yüksek korelasyona sahip değișkenlerin etki derecesi

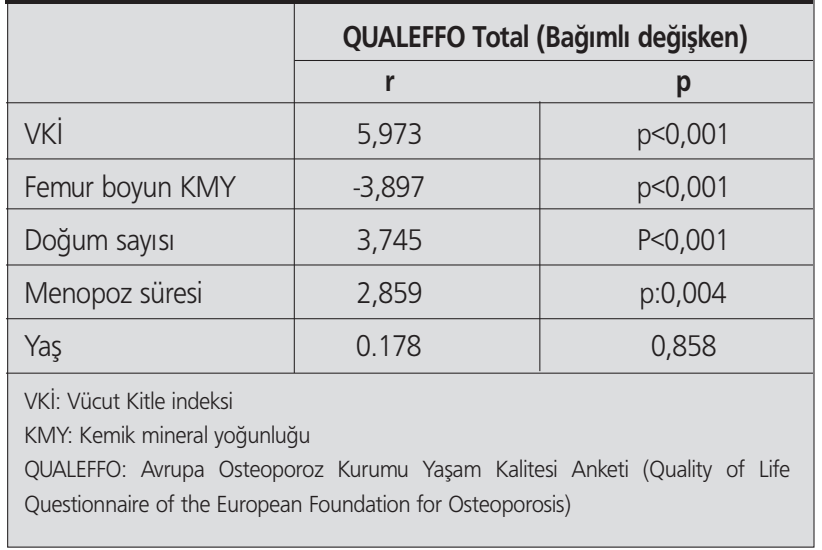

olmayan PMO'lu kadın hastaları dahil ettiğimiz çalışmamızda yaşam kalitesini değerlendirmek için osteoporozlu olgularda doğru ve tekrarlanabilir sonuçlar verdiği çalışmalar ile gösterilmiş olan ve osteoporoza özgü ölçütlerden olan QUALEFFO ölçeğini kullandık (2). Sonuç olarak kırığı olmayan PMO'lu kadınlarda yaşam kalitesinin tüm bileşenlerinde hem osteopenik hem de normal KMY'li gruba göre belirgin kötüleşme olduğunu belirledik. Ancak osteopenik grup ile normal KMY'li grup arasında yaşam kalitesi bileşenleri yönünden fark yoktu. Çalışmamızda katılımcılarımızın QUALEFFO toplam skoruna etki eden en önemli faktör hastada osteoporozun olması idi. Bu sonuçlar kırık olmasa bile osteoporozun kadınlarda yaşam kalitesi üzerine ciddi olumsuz etkilerinin olduğunu göstermektedir. PMO'lu kadınlarda yaşam kalitesini QUALEFFO ile değerlendiren farklı çalışmalar 
sonuçlarımızı destekler şekilde osteoporozlu hastalarda yaşam kalitesinin bozulduğu bildirmiş̧ir $(14,16)$. Benzer olarak PMO'lu kadınlarda yaşam kalitesini SF-36 ve NPH (Notthingham Health Profile) ile değerlendiren iki çalışmada da osteoporozlu hastalarda yaşam kalitesinin bozulduğu bildirilmiştir $(17,18)$. Ancak bu çalışmalarda bizim çalışmamızdan farklı olarak değişen oranlarda kırığı olan hastalar da dahil edilmiştir. Yakın zamanda yürütülen bir çalışmada çalışmamıza benzer şekilde vertebral kırığı olmayan osteoporotik ve osteopenik hastalar arasında genel olarak QUALEFFO ile değerlendiren yaşam kalitesinde farklıık olmamasına rağmen fiziksel fonksiyon düzeyi osteoporotik hastalarda daha düşük bulunmuştur (8). Sonuçlarımızdan farklı olarak Romagnoli ve ark. osteopenik ve kırığı olmayan PMO'lu hastalar arasında QUALEFFO ile değerlendiren yaşam kalitesi değerlerinde fark tespit etmemişlerdir (5).

Çalışmamızda PMO'lu kadınlarda ileri yaş, VKi'inde artış, düşük eğitim seviyesi, düşük gelir düzeyi, artmış doğum sayısı, erken menopoz ve düşük femur boyun KMY değerlerinin yaşam kalitesini negatif yönde etkilediğini tespit ettik. Illaveten PMO'lu kadınlarda yaşam kalitesi ile en yüksek korelasyona sahip değişkenleri lineer regresyon modeline alındığında PMO'lu kadınlarda yaşam kalitesinin primer belirleyicileri olarak VKi, femur boyun KMY, doğum sayısı ve menopoz süresi tespit edildi. Bu faktörlerin yaşam kalitesi üzerindeki etkileri çeşitli çalışmalarda gösterilmiştir. $(9,11,12,16,18)$

Çalışmamızda PMO'lu kadın hastalarımızın yaş ortalamaları, osteopenik ve normal KMY'li gruba kıyasla istatistiksel olarak anlamlı derecede yüksekti. Osteoporoz gelişiminde yaşın önemli bir faktör olduğu göz önünde bulundurulursa bu beklenen bir bulgudur $(19,20)$. Çalışmamızın sonuçları PMO'lu kadınlarda ileri yaşın yaşam kalitesini olumsuz yönde etkilediğini göstermektedir. Sonuçlarımıza paralel olarak PMO'lu kadınlarda yaşam kalitesi QUALEFFO ile değerlendiren farklı çalışmalarda da, ileri yaşın yaşam kalitesi üzerinde negatif etkiye yol açtığı bildirilmiştir $(11,16,21)$. Insanlarda biyolojik yaşlanmanın yanısıra psikolojik, sosyal yetenek ve işlevlerde de değişiklikler olmaktadır (22). Bu bilgiden yola çıkarak ileri yaşın genel olarak yaşam kalitesini olumsuz etkileyebileceğini, kronik bir hastalık olan osteoporozun eklenmesinin yaşam kalitesindeki bu olumsuz etkilenmeyi artırabileceği kanısındayız.

Ayrıca kilo artışının fiziksel kondüsyon üzerinde ilerleyici bir kayıba yol açı̆ı̆ı, osteoartiküler yapıda hasarlanmaya ve solunum problemlerinin oluşumunda artışa sebep olduğu, bunun yanı sıra yaşamın sosyal, kültürel ve davranışsal komponentlerinde meydana getirdiği bozulma ile yaşam kalitesi üzerinde belirgin negatif etki gösterdiği rapor edilmiştir (23). Bu durum PMO'lu kadınlarda yüksek VKi'nin yaşam kalitesi üzerine olumsuz etkilerinin olabileceğini göstermektedir. Çalışmamızda PMO'lu kadınlarda VKi değerleri arttıkça QUALEFFO total skoru olumsuz yönde yükseliyordu. İlaveten osteopenik ve normal KMY'li grupta da yüksek VKi değerleri ile QUALEFFO total skoru olumsuz yönde yükseliyordu. Bu sonuçlarımız postmenopozal kadınlarda artmış VKI'nin yaşam kalitesini olumsuz etkilediğini göstermektedir. Farklı çalışmalarda da, PMO'lu hastalarda VKi'deki artışın, yaşam kalitesini negatif yönde etkileyen bir faktör olduğu gösterilmiştir $(6,16,21,24,25)$. Bu nedenle özellikle kilo alımının hızlandığı postmenopozal dönemde, osteoporoz hastalarına hazırlanan tedavi programı çerçevesinde, uygun kiloya sahip olma ve bunu koruma yönünde gerekenler yapılmalıdır.

Bu çalışmada, araştırdığımız diğer bir parametre de eğitim düzeyi idi. Eğitim düzeyi ve yaşam kalitesi ilişkisinin incelendiği çalışmalar farklı sonuçlar bildirilmiştir. Başaran ve ark. düşük eğitim düzeyinin PMO'lu hastalarda yaşam kalitesini olumsuz etkilediğini bildirmişlerdir (21). Daha önce yürütülen bir çalışmada ise, osteoporozlu kadınlarda, yalnızca üniversite düzeyindeki eğitimin yüksek yaşam kalitesi ile ilişkili olduğu tespit edilmiştir (24). Solak ve ark. PMO'lu ve osteopenili hastalar ile yürüttükleri çalışmada eğitim düzeyi ile yaşam kalitesi arasında istatistiksel olarak anlamlı bir korelasyon tespit edememişlerdir (6). Bizim çalışmamızda eğitim düzeyinde düşüş, yaşam kalitesini negatif yönde etkileyen bir faktör olarak karşımıza çıkmaktadır. Ancak çalışmamıza dahil edilen PMO'lu kadınların eğitim düzeyinin düşük (\%18,4'ü okuma yazması yok, \%74,2'si ilköğrenim mezunu) olmasının sonuçları etkilediğini düşünüyoruz.

Bu çalışmada irdelediğimiz bir diğer faktör menopoz süresi idi. Uzun menopoz süresi, çalışmamızda yaşam kalitesini negatif yönde etkileyen bir faktör olarak karşımıza çıkmaktadır. Benzer şekilde yapılan çalışmalarda PMO'lu kadınlarda uzun menopoz süresinin yaşam kalitesi bileşenleri üzerinde negatif etkiye sahip olduğunu bildirilmiştir $(16,21)$. Menopozal dönemde yeterli sağlık bakımı almayan birçok kadında kronik hastalıkların gelişebilmekte ve yaşam kalitesi olumsuz yönde etkilenebilmektedir (26). Bu nedenle kadın hayatının üçte birinden fazlasını kapsayan menopoz döneminde kişinin yaşam kalitesinin artırılması için uygun sağlık bakımının verilmesi çok önemlidir.

Yapılan çalışmalarda KMY'si düşük olan yaşlıların kas güçlerinin ve yürüme hızlarının da düşük olduğu bildirilmiştir $(27,28)$. Fiziksel performans, kas gücü, denge, yürüme hızıyla doğrudan ilişkili olup yaşılırın yaşamlarını bağımsız olarak sürdürebilmeleri ve yaşam kaliteleri için çok önemlidir. $(29,30,31,32)$. Bizim çalışmamızda düşük femur boyun KMY değerlerinin yaşam kalitesini negatif yönde etkilediğini tespit ettik. Ancak L1-4 KMY değerleri ile yaşam kalitesi arasında ilişki tespit edemedik. PMO'lu kadınların dahil edildiği bazı çalışmalar, düşük femur boyun ve lomber vertebra KMY değerlerinin QUALEFFO ile değerlendirilen yaşam kalitesini olumsuz etkilediğini bildirilirken $(8,12)$, bazı çalışmalar ise femur boyun ve lomber vertebra KMY değerleri ile yaşam kalitesi arasında bir ilişki bildirmemişlerdir (14,16,21,33). Bu nedenle KMY ve yaşam kalitesi arasındaki ilişkiyi tespit edebilmek için daha kapsamlı çalışmalara gerek olduğunu düşünüyoruz.

Artmış doğum sayısı PMO'lu hastaların yaşam kalitesini negatif yönde etkileyen bir faktör olarak karşımıza çıkmaktadır. Aşırı doğurganlık ve bakmakla sorumlu olduğu birey sayısının fazla olması kadın hayatını etkileyen önemli bir faktördür (26). Biz artmış doğum sayısının, ilgilenmek zorunda kalınan aile fert sayısının artmasına ve kadının kendine ayırdığı zamanın kısıtlamasına neden olarak yaşam kalitesini olumsuz yönde etkileyebileceğini düşünmekteyiz.

Çalışmamız, dahil edilen katılımcı sayısının fazla olmasına rağmen bazı kısıtılıklara sahiptir. Illk olarak katılımcıların serum vitamin D düzeyi tespit edilemedi. Yapılan çalışmalarda yetersiz veya eksik $D$ vitamini düzeylerinin fiziksel fonksiyonları, vitalite, enerji düzeyi ve sosyal fonksiyonları etkileyerek yaşam kalitesini azalttığı gösterilmiştir $(21,34)$. Katılımcılarımızın yaşadığı ortamı 
bu çalışmada belirlenememiştir. Yakın zamanda yürütülen bir çalışmada, katılımcılar yalnız veya ailesi ile yaşayanlar olarak gruplandırılmış ve sonuçta yaşanılan ortamın yaşam kalitesi üzerinde etkili olduğu bildirilmiştir (16).

Bu çalışmanın sonuçları, kırığı olmayan PMO'lu kadınların yaşam kalitesinin olumsuz yönde etkilendiğini ve yaşam kalitesini etkileyen sosyodemografik, klinik ve hastalığa spesifik pek çok faktörün bulunduğunu göstermektedir. Bu nedenle osteoporoz ile ilgilenen sağlık profesyonelleri, PMO'lu kadınları değerlendirme, tedavi ve takipleri sırasında kırı̆̆ı olmasa da yaşam kalitesini mutlaka göz önünde bulundurmalı ve radyografik ölçümler, biyokimyasal belirteçler ile birlikte yaşam kalitesi bileşenlerini de takip etmelidirler.

\section{Kaynaklar}

1. The WHOQOL Group. The development of the World Health Organisation quality of life assessment instrument (the WHOQOL). In: Orley J, Kuyken W, eds. Quality of Life Assessment: International Perspectives. Heidelberg:Springer Verlag, 1994:41-57.

2. Lips P, Van Schoor NM. Quality of life in patients with osteoporosis. Osteoporosis Int 2005;16:447-55. Epub 2004 Dec 18.

3. World Health Organization. Prevention and management of osteoporosis. Technical Report Series 921. World Health Organization, Geneva 2003.

4. World Health Organisation. Assesment of fracture risk and its application to screening for postmenopausal osteoporosis. Technical Report Series 843 WHO, Geneva 1994

5. Romagnoli E, Carnevale V, Nofroni I, D'Erasmo E, Paglia F, De Geronimo $S$, et al. Quality of life in ambulatory postmenopausal women:the impact of reduced bone mineral density and subclinic vertebral fractures. Osteoporos Int 2004;15:975-80. Epub 2004 Apr 30.

6. Solak Ö, Fidan F, Gökçe IY, Demirdal ÜS, Çalışkan G, Kavuncu V, ve ark. Osteoporoz ve osteopenili olgularda pulmoner fonksiyonlar ve yaşam kalitesi. Osteoporoz Dünyasından 2009;15:11-6.

7. Sindel D. Tanı yöntemleri. Türkiye Klinikleri Fiziksel Tıp ve Rehabilitasyon. Osteoporoz Özel Sayısı 2002;2:17-29.

8. Nur H, Toraman NF. Postmenopozal osteoporozda vertebral kırıkların yaşam kalitesine etkisi. Türk Osteoporoz Dergisi 2011;17:81-4

9. Bianchi ML, Orsini MR, Saraifoger S, Ortolani S, Radaelli G, Betti S. Quality of life in post-menopausal osteoporosis. Health Qual Life Outcomes 2005;3:78

10. Gülbahar S, El Ö, Altay C, Şahin E, Köroğlu F, Akgün B, ve ark. Postmenopozal osteoporozda vertebral kırık ve yaşam kalitesi arasındaki ilișki. Osteoporoz Dünyasından 2007;13:23-7.

11. Oleksik AM, Ewing $S$, Shen $W$, van Schoor NM, Lips P. Impact of incident vertebral fractures on health related quality of life (HRQOL) in postmenopausal women with prevalent vertebral fractures. Osteoporos Int 2005;16:861-70. Epub 2004 Nov 19.

12. Paker N, Buğdaycı D, Dere D, Tekdöş D, Erbil E, Dere C. Relatıonshıp between bone densıty and qualıty of lıfe in postmenopausal osteoporosis. Turkish Journal of Geriatrics 2012;15:19-23.

13. Genant HK, Wu CY, Von Kuijk C, Nevitt MC. Vertebral fracture assessment using a semiquantitive technique. J Bone Miner Res 1993:8:1137-48

14. Koçyiğit H, Gülseren S, Erol A, Hizli N, Memis A. The reliability and validity of the Turkish version of quality of life questionnaire of the european foundation for osteoporosis (QUALEFFO). Clin Rheumatol 2003;22:18-23

15. Cook DJ, Guyatt GH, Adachi JD. Epstein RS, Juniper EF, Austin PA, et al. Development and validation of the mini osteoporosis quality of life questionnnaire (QOLQ) in osteoporotic women with back pain dueto vertebral fractures. Osteoporosis Int 1999:10:207-13.
16. Sezer N, Tomruk-Sütbeyaz S, Kibar S, Köseoğlu F, Aras $M$. Postmenopozal osteoporozda yaşam kalitesinin belirteçleri. FTR Bil Der 2009;12:19-25

17. Aranha LL, Mirón Canelo JA, Alonso Sardón M, Del Pino Montes J, Sáenz González MC. Health-related quality of life in Spanish women with osteoporosis. Rev Saude Publica 2006:40:298-303. Epub 2006 Mar 29.

18. Adıgüzel $D$, Gündüz $\mathrm{OH}$, Bodur $H$, Yüceli $M$. Qualıty of lıfe ın osteoporosıs. Romatizma 2000;15:173-9

19. Yılmaz H, Erkin G, Demir Polat HA, Küçüksen S, Sallı A, Uğurlu H. Effects of reproductive factors on bone mineral densitometry. Turkish Journal of Osteoporosis 2012;18:8-12.

20. Koyuncu $H$, Aktaş $i$, Dinç $A$, Özkul $i$, Aydın T, Yücel $E$, ve ark. Postmenopozal osteoporozda depresyonun demografik özellikleri kemik mineral yoğunluğu ve yaşam kalitesi arasındaki ilişkinin incelenmesi. Osteoporoz Dünyasından 2003;9:89-93.

21. Başaran S, Güzel R, Benlidayı iC, Uysal FG. Postmenopozal ve senil osteoporozlu kadınlarda yaşam kalitesinin ve belirleyicilerinin değerlendirilmesi. Türk Fiz Tıp Rehab Derg 2006;52:31-6.

22. Bozcuk AN, Demirsoy A. Yaşlanmanın biyolojisi. In:Gökçe-Kutsal Y, Çakmakcı M, Ünal S editors. Geriatri 1. Medico Graphics Ajans ve Matbaası. Ankara, Türkiye, 1997;7-21.

23. Marchesini G, Solaroli E, Baraldi L, Natale S, Migliorini S, Visani F, et al. Health-related quality of life in obesity: the role of eating behaviour. Diabetes Nutr Metab 2000;13:156-64.

24. Papaioannou A, Joseph L, loannidis G, Berger C, Anastassiades T, Brown JP, et al. Risk factors associated with incident clinical vertebral and nonvertebral fractures in postmenopausal women: the Canadian Multicentre Osteoporosis Study (CaMos). Osteoporos Int 2005;16:568-78. Epub 2004 Oct 27.

25. Keskin D, Borman P, Eser F, Bodur H, Köse K. Yaşlılarda fiziksel aktivite, kemik mineral yoğunluğu ve yaşam kalitesinin değerlendirilmesi. Turkish Journal of Geriatrics 2008:11:113-8

26. Yurdakul M, Eker A, Kaya D. Menopozal dönemdeki kadınların yaşam kalitesinin değerlendirilmesi. Fü. Sağ. Bil. Derg 2007;21:187-93.

27. Lindsey C, Brownbill RA, Bohannon RA, llich JZ. Association of physical performance measures with bone mineral density in postmenopausal women. Arch Phys Med Rehabil 2005;86:1102-7.

28. Taaffe DR, Simonsick EM, Visser M, Volpato S, Nevitt MC, Cauley JA, et al. Lower extremity physical performance and hip bone mineral density in elderly black and white men and women: Cross-sectional associations in the Health ABC study. J Gerontol A Biol Sci Med Sci 2003:58:M934-42.

29. Karinkanta S, Heinonen A, Sievanen H, Uusi-Rasi K, Kannus P. Factors predicting dynamic balance and quality of life in home-dwelling elderly women. Gerontology 2005;51:116-21.

30. Kwon J, Suzuki $\mathrm{T}$, Yoshida $\mathrm{H}$, et al. Association between change in bone mineral density and decline in usual walking speed in elderly community-dwelling Japanese women during 2 years follow-up. J Am Geriatr Soc 2007;55:240-4

31. Shinkai S, Watanabe S, Kumagai S, Fujiwara $Y$, Amano $H$, Yoshida $H$, et al. Walking speed as a good predictor for the onset of functional dependence in a Japanese rural community population. Age Ageing 2000;29:441-6.

32. Stel VS, Pluijm SM, Deeg DJ, Smith JH, Bouter LM, Lips P. Functional limitations and poor physical performance as independent risk factors for self-reported fractures in older persons. Osteoporosis Int 2004;15:742-50. Epub 2004 Mar 11.

33. Paker N, Soy D, Bardak A, Erbil M, Ersoy S, Uysal E. Osteoporozda yaşam kalitesi: Cinsler arasında fark var mı? Osteoporoz Dünyasından 2004; 10:112-7.

34. Akpınar $P$, içağasıoğlu $A$. D vitamininin yaşam kalitesi ile ilişkisi. Türk Osteoporoz Dergisi 2012;18:13-8. 